\title{
PROGRAMA DE MOBILIDADE ACADÊMICA INTERNACIONAL EM ENFERMAGEM: relato de experiência
}

\author{
M ariana G onçalves de O LIVEIRAa, L orita M arlena F reitag PA G LIU CA ${ }^{b}$
}

\section{RESUMO}

Experiência de estudos no exterior, intercâmbio, agrega valor profissional e pessoal. Objetivou-se descrever experiência discente em prog rama de mobilidade acadêmica inter nacional. Estudo de 2008 até 2009 no Brasil ena Espanha. Enfatizaram-se as vivências, observações e atividades realizadas, por acreditar que a formação de discentes e pesquisadores não se restringe somente à univer sidade e ao país de origem, dando possibilidades de experiências e conhecimentos. Conclui-se, essa oportunidade promoveu repercussões no amadurecimento psicológico, cultural, social e científico.

Descritores: Inter nacionalidade. Estudantes de enfermagem. I ntercâmbio educacional inter nacional.

\section{RESUMEN}

Experiencia de estudiar en el extranjero, o de cambio, añade valor al crecimiento profesional y personal. E I objetivo fue describir la experiencia del estudiante en programa de movilidad académica internacional. E studio desar rollado desde 2008 hasta 2009 en B rasil y E spaña. D estacar las experiencias, observaciones y actividades realizadas durante el período de movilidad, en la creencia de que la formación de estudiantes e investigadores no se restringe a la universidad y el país de origen, dando posibilidades de nuevas experiencias y conocimientos diferenciados. Se concluye que esta oportunidad ha promovido un profundo efecto sobre su perfil psicológico, cultural, social y científico.

Descriptores: Internacionalidad. E studiantes de enfermería. Intercambio educacional internacional. Título: P rograma internacional de movilidad académica en enfermería: relato de experiencia.

\section{ABSTRACT}

An experience of studying abroad, or of academic exchange, really adds value to the professional and per sonal development of exchange students. T his report aims to describe a student's experience in an international academic mobility program. It was developed from 2008 to 2009 in Brazil and Spain. The experiences, observations and activities of the student were emphasized, believing that the training of students and researchers is not only restricted to the university and the students' home country, and that it is important to have possibilities of new experiences and differentiated know ledge The conclusion is that this opportunity promoted a profound effect on psychological, cultural, social and scientific development of the exchange student.

Descriptors: I nternationality. Students, nursing. International educational exchange.

Title: International academic mobility program in nursing: experience report.

\footnotetext{
a Enfermeira, M estranda do Programa de Pós-Graduação em Enfermagem da U niversidade Federal do Ceará (UFC), Fortaleza, Ceará, Brasil.

b D outora em Enfermagem, Professora Titular do Departamento de Enfermagem UFC, Pesquisadora do Conselho Nacional de D esenvolvimento Científico e T ecnológico (CN Pq), Fortaleza, Ceará, Brasil.
} 


\section{INTRODUÇÃO}

Com a globalização, o mundo acadêmico e trabal ho são inter-relacionados. A educação era consider ada transmissão de alta cultura, social ização atuação diante da sociedade e construção de caráter. Hoje, está voltada para o trabalho, preparar profissionais com conhecimento, aptidões e capazes de acompanhar o desenvolvimento tecnológico. 0 trabal ho considerado mão de obra e força física, passou a ser intel ectual, qualificado, resultado de uma for mação acadêmica completa e diferenciado(1). Aí a importância em sair do tradicional ismo e conhecer outras culturas, realidades e educação. Buscar expandiu o sistema acadêmico internacional depende da decisão individual e de recurso financeiros e operacionais para isto.

0 multiculturalismo advém da internacionalização do ensino superior, a partir de inter ações com pessoas de diferentes origens e culturas, assim formam alunos mais críticos e reflexivos, que buscam conhecer as distintas visões sobre o mundo (2). D essa forma, será mais fácil acompanhar mudanças da sociedade e mercado de trabalho com uma postura crítica e reflexiva ${ }^{(3)}$. Alunos que cursam desde o nível médio até o pós-doutorado serão beneficiados por um novo programa de internacionalização, o Ciências sem F ronteira(4).

Esta mobilidade possibilita estudar em outra instituição e, objetiva o enriquecimento cultural e científico, melhoria do currículo do aluno e fluência em outros idiomas, permitindo desenvolvimento e promoção de uma educação de qualidade ${ }^{(5)}$. Experiência desse tipo agrega valor ao crescimento profissional e pessoal. Entretanto, é preciso estar preparado, pois a iniciativa requer el evada dose de tolerância, desprendimento e capacidade de lidar com imprevistos, a ausência de familiares e amigos; as diferenças culturais, de clima, de hábitos e de valores.

Permite proveito e vantagens que vão além do aprendizado, mas também no desenvolvimento psicológico, autoconfiança, amadurecimento, independência, capacidade de relacionar-se e, sentir-se "um cidadão do mundo". Hoje, essa busca deve-se ao fato das empresas valorizarem os profissionais que dominam outros idiomas e outras culturas, porquanto esta é uma oportunidade para se ampliar a visão de mundo e, ao mesmo tempo enriquecer-se culturalmente ${ }^{(6)}$. 0 intercâmbio é forma de trocar informações, crenças, culturas, conhecimentos. A experiência de viver em outro país propicia conhecer hábitos diferentes, abre nova perspectiva, supera dificuldades, pois o intercambista precisa se adaptar ao ambiente, enfrentar desafios e cres$\operatorname{cer}^{(7)}$.

A lém de viver a experiência, é preciso relatá-la com vistas a torná-la conhecida pelos estudantes para incentivar a participação de novos alunos interessados nesta modal idade acadêmica ${ }^{(8)}$. Portanto, o objetivo é descrever a experiência de estudante de graduação em Enfermagem, na categoria denominada mobilidade acadêmica. N este relato enfatizaram-se as vivências, observações e atividades no período de preparação e realização da mobilidade, acreditando que a formação discentes e de pesquisadores, além do país de origem, possibilita experiências e conhecimentos diferenciados.

\section{RELATO DA EXPERIÊNCIA DO PROGRAMA DE MOBILIDADE ACADÊMICA}

Decidir a mobilidade ocorreu ao cursar 0 50 semestre do Curso de G raduação em E nfermagem da U niversidade F ederal do Ceara (U F C) quando já era, há dois anos, bolsista de Iniciação Científica do Conselho $\mathrm{N}$ acional de $\mathrm{D}$ esenvolvimento $\mathrm{Ci}$ entífico e T ecnológico participando de projeto de pesquisa. Percebe-se forte desenvolvimento de pesquisas na E nfermagem, por meio de Grupos de Pesquisa, cientistas tem disseminado críticas nos variados setores de saúde ${ }^{(9)}$. A Coordenação de A ssuntos Internacionais da U FC orienta no site www.cai.ufc.br os passos para inscrição no programa e as facul dades conveniadas, escolheu-se a U niversidade de Santiago de Compostela (USC), na E spanha. Logo, a mobilidade ocorreu através do convênio entre a UFC e a U SC com o reconhecimento mútuo dos créditos cursado.

A os intercambistas a USC oferece curso básico de espanhol por um mês e exige a chegada antecipada ao início das aulas da graduação. 0 aperfeiçoamento da língua estrangeira torna 0 aluno mais preparado para o mercado. A hospedagem na residência universitária é precedida de processo de seleção, a demanda é maior do que a oferta. Dividir apartamento com pessoas de nacionalidades diferentes forçou assumir obrigações domésticas somadas a aulas, estágios e pesquisa, mas não comprometeu o lazer: atividades físicas no clube e no parque, compras, passeios, happy hour, shows e via- 
gens internacionais.0s estudos tiveram início em setembro de 2008 e término em março de 2009 na Espanha, com quatro disciplinas com aprovação. Comparando o ensino, evidenciou diferenças culturais entre aluno e professor do Brasil e da Espanha. Ao retornar do exterior, o aproveitamento dos estudos no Brasil permitiu continuar na mesmo turma e a colação de grau no devido tempo.

Para enriquecer conhecimentos e prática, 0 Curso de Enfermagem da USC propiciou estágio extracurricular, com duração de seis meses, no Hospital U niversitário nos setores: psiquiatria, urgência, pediatria e traumatologia. Foi oportuno observar o modo de cuidar dos profissionais destes locais e aprender a trabal har com eles.

Conhecer equipamentos e materiais, tecnologias e arquiteturas estimularam relembrar as vivências do Brasil e compará-las com esta realidade. Estagiar aguçou a capacidade de observação e comparação entre as duas realidades. A o final, as horas trabal hadas foram certificadas permitindo aproveitamento curricular e processos seletivos no Brasil.

0 ambiente universitário expande conhecimento por meio da pesquisa, do ensino e da extensão. Para isso usa estratégias, dentre el as a mobilidade acadêmica que permite 0 discente ampliar e conhecer experiências e estudos.

Então, surgiu oportunidade de expor experiência como bolsista de Iniciação Científica no Brasil para docente e discente da U SC. D escreveu-se a investigação sobre 0 cuidado das mães cegas aos seus fil hos, no Brasil e continuado na E spanha ${ }^{(7)}$. A metodologia replicada permitindo estudo comparativo entre as duas culturas ${ }^{(8)}$. Com esse incentivo da U SC abriu-se 0 acesso à Organização $\mathrm{N}$ acional Cegos na E spanha (ON CE ), e também a lojas personalizadas, domicílios, casas lotéricas que são locais de trabal ho de muitos cegos.

$N$ esse contato com os cegos na Espanha registrou-se a diferença da acessibilidade física e à atitude social de aceitação da pessoa com deficiência. Esta experiência foi descrita em trabalhos científicos posteriormente ${ }^{(10)}$. Sabe-se que para que todo ser humano possa viver com dignidade e de forma plena e positiva, é de fundamental o acesso à educação e à saúde ${ }^{(11)}$. Conforme observado a Espanha é um país de tradição de aceitação e integração dos deficientes visuais.

Ainda no Brasil enviaram-se trabal hos científicos para o XII E ncuentro Internacional de In- vestigación em Enfermería e 60 Coloquio Bianual Joanna Briggs, aceitos e apresentados em Córdoba ${ }^{(12)}$. O bteve-se 0 apoio da orientadora no Brasil, co-autora dos trabalhos, que financiou a inscrição do congresso. A coordenação do Curso de Enfermagem da USC patrocinou a estadia e passagem. 0 congresso revelou-se enriquecedor, de dimensões surpreendentes.

0 investimento financeiro para mobilidade acadêmica foi custeada pelo próprio aluno. As economias da bolsa de Iniciação Científica, parte da poupança ea ajuda dos pais contribuíram para isto. A bolsa de I niciação Científica foi mantida com a autorização do Conselho $\mathrm{N}$ acional de D esenvolvimento Científico e T ecnológico (CN P q), mediante consulta prévia onde se justificou a continuidade do projeto no exterior.

À quela época não existia possibilidade de apoio financeiro para a mobilidade acadêmica custeado por agências gover namentais para a área da E nfermagem. Porém, outros cursos de graduação contam com um programa de duplo diploma financiado pel o governo ${ }^{(6)}$. A credita-se que havendo demanda da E nfermagem, será destinado cotas para estes estudantes.

\section{CONSIDERAÇÕES FINAIS}

Além da convivência acadêmica, houve crescimento pessoal, cultural e social. Conhecer países, conquistar amizades, exercitar idiomas e observar atitudes estrangeiras fizeram parte desta experiência.

$\mathrm{Na}$ USC, 0 apoio sempre atendeu prontamente as necessidades e facilitaram a estada. As dificuldades aconteceram, são naturais na adaptação ao novo ambiente e nas relações pessoas. Portanto, não merecem destaque.

0 incentivo e a ajuda da orientadora no Brasil foram fundamentais à concretização da mobilidade, sempre que necessário houve suporte mesmo à distância. I mprescindível citar o apoio da família. 0 relato desta experiência teve como meta incentivar interessados a realizarem a mobilidade acadêmica. Compartilhar este sucesso é forma de disponibilizar informações para que outras pessoas conheçam este caminho. A inda se colhem os frutos dessa vivência e estimula-se a repetir 0 intercâmbio, agora na qualidade de pós-graduando. 


\section{REFERÊNCIAS}

1 Santos BS. Pela mão de Alice: o social e o político na pós-modernidade. 13a ed. São Paulo: Cortez; 2010.

2 Lima M C, M aranhão CM SA. Políticas curriculares da internacionalização do ensino superior: multiculturalismo ou semiformação? Ensaio Aval Pol Públ E duc. 2011;19(72):575-98.

3 Rodrigues EC, Grego SM D, Romanatt M J. A problematização da docência universitária no contexto do capital ismo universitário. Rev I bero-A m E stud E duc [ Internet] . 2010 [ citado 2012 fev 10] . 5(3). D isponível em: http:/ / seer.fclar.unesp.br/iberoamericana/ article/ download/ 3705/ 3465.

4 M inistério da E ducação (BR). Programa "Ciências sem F ronteira" oferece formação no exterior a 75 mil estudantes. Brasília (DF); 2012.

5 U niversidade Federal do Ceará, Coordenadoria de Assuntos Internacionais. M obilidade acadêmica [ Internet] . Fortal eza; 2010 [ citado 2012 fev 10] . Disponível em: http:// www.cai.ufc.br/ mobilidade.htm.

$6 \mathrm{G}$ uia do E studante E rasmus. Programa Sócrates [ I nternet] . L isboa: A gência N acional para os Programas Sócrates e L eonardo da Vinci; 2004 [ citado 2012 fev 11] . D isponível em: http:/ / www.ff.up.pt/ grex/ ficheiros/ G uiaE studanteE rasmus2004.pdf.
7 Souza KV. Intercâmbio educacional internacional na modalidade doutorado sanduíche em enfer magem: relato de experiência. Esc Anna N ery. 2008;12(2):358-63.

8 D antas RA, Pagliuca LM F, Carvalho ALRF, A breu W C. D outorado-sanduícheem E nfer magem: relato de experiência. Esc Anna N ery. 2009;13(2):425-9.

9 Gomes DC, Backes VM S, Lino M M , Canever BP, Ferraz F, Schveitzer MC. Produção científica em Educação em Enfermagem: grupos de pesquisa Rio de Janeiro e M inas Gerais. Rev Gaúcha Enferm. 2011;32 (2):330-7.

10 Rebouças CBA, Pagliuca LM F. Programa de pósgraduação em enfer magem na perspectiva discente. Rev Enferm UERJ. 2010;18(1):138-42.

11 A lencar R, Ciosak S, Bueno S. T raining of academic nurses: the need to place in the curriculum of the subject of human sexuality. Online Braz J Nurs [ Inter net] . 2010 [ cited 2012 F eb 10];9(2). Available from: http:/ / www.objnursing.uff.br/index.php/ nursing/ article/ view/ 1064.

12 Oliveira M G, F élix D P, Pagliuca L M F. Relato de las madres ciegas sobre la experiencia de la lactancia. In: A nal es do $12^{\circ}$ E ncuentro I nternacional de Investigación en Enfermería, 60 Coloquio Bianual Joanna Briggs; 2008 nov 12-15; Córdoba, España. Córdoba: Investén; 2008.

\section{Endereço da autora / Dirección del autor / Author's address:}

L orita M arlena F reitag Pagliuca

Rua A lexandre Baraúna, 1115, Rodolfo T eófilo

60430-160, Fortaleza, CE

E-mail:pagliuca@ufc.br
Recebido em: 28/ 03/ 2011

A provado em: 01/ 03/ 2012 